\title{
Psychiatric comorbidity and mortality in patients with anorexia nervosa
}

\author{
Tomoyuki Kawada ${ }^{1}$ (D)
}

Received: 9 January 2020 / Accepted: 8 February 2020 / Published online: 17 February 2020

○) Springer-Verlag GmbH Germany, part of Springer Nature 2020

Himmerich et al. investigated the effect of psychiatric comorbidities on the all-cause mortality of patients with anorexia nervosa (AN) [1]. The adjusted hazard ratios of substance use disorders (SUD), affective disorders (AD), and personality disorders (PD) for mortality were not statistically significant. However, the existence of comorbidities, SUD, or PD, presented an increasing trend of mortality. Although some information has been presented in the discussion of the original article, I have three concerns about this study: (1) the small number of deaths in the cohort may have led to insufficient statistical power, (2) the lack of information on cause-specific mortality, and (3) questions about possible additive or synergistic effects.

Firstly, the number of events was 43 . Although there was no significant association between psychiatric comorbidities and all-cause mortality, this should be viewed cautiously due to the small number of included events. Peduzzi et al. reported that the number of events per variable should be kept to ten or higher [2,3]. As there is a possibility of insufficient statistical power for the analysis, a continuous survey is needed to conduct stable estimates.

Secondly, cause-specific mortality might also be important in patients with AN. Although it is challenging to sum the number of events, specific causes of death, such as suicide, should be grouped. Additionally, the mechanism of the association to the discrepancies among SUD, PD and AD is unclear and should be further investigated.

Finally, there is a risk of mortality in persons with antisocial personality disorder [4]. As there is a risk of mortality in patients with $\mathrm{PD}$, an additive or synergistic effect of AN and PD for all-cause mortality should be ascertained. Due to the small number of events, further analyses cannot be conducted. A risk estimation should be performed with a greater number of samples and events.

\section{Compliance with ethical standards}

Conflict of interest There is no conflict of interest in this study.

Disclosure statement The author has indicated no financial support.

\section{References}

1. Himmerich H, Hotopf M, Shetty H, Schmidt U, Treasure J, Hayes RD, Stewart R, Chang CK (2019) Psychiatric comorbidity as a risk factor for mortality in people with anorexia nervosa. Eur Arch Psychiatr Clin Neurosci 269:351-359

2. Peduzzi P, Concato J, Feinstein AR, Holford TR (1995) Importance of events per independent variable in proportional hazards regression analysis. II. Accuracy and precision of regression estimates. J Clin Epidemiol 48:1503-1510

3. Concato J, Peduzzi P, Holford TR, Feinstein AR (1995) Importance of events per independent variable in proportional hazards analysis. I. Background, goals, and general strategy. J Clin Epidemiol 48:1495-1501

4. Krasnova A, Eaton WW, Samuels JF (2019) Antisocial personality and risks of cause-specific mortality: results from the Epidemiologic Catchment Area study with 27 years of follow-up. Soc Psychiatr Psychiatr Epidemiol 54:617-625
Editorial Responsibility: Andrea Schmitt.

Tomoyuki Kawada

kawada@nms.ac.jp

1 Department of Hygiene and Public Health, Nippon Medical School, 1-1-5 Sendagi, Bunkyo-Ku, Tokyo 113-8602, Japan 